\title{
CREATIVIDAD LÉXICA Y DISCURSIVA EN EL LENGUAJE ORAL INFANTIL
}

\author{
MARÍA DEL CARMEN QUILES CABRERA \\ Universidad de Almeria
}

\section{RESUMEN}

El presente artículo se centra en el lenguaje de las primeras edades, su capacidad creativa y su discurso oral. En primer lugar, establecemos una reflexión en torno a las distintas concepciones teóricas que han tratado de explicar cómo se adquieren las lenguas y su papel en nuestra condición de seres sociales. Además, nos acercamos al plano de la educación lingüística tras ofrecer una aproximación a los usos léxicos y discursivos en la infancia a través de la presentación y descripción de muestras que ponen de manifiesto toda una serie de fenómenos; oscilan desde la transgresión fonética y la peculiar configuración de los discursos al sentido estético en el uso de las palabras.

Palabras ClaVE: creatividad, discurso oral, lenguaje infantil, léxico, competencia comunicativa.

\section{ABSTRACT}

The present article focuses on language at early ages, its creative capacity and their oral speech. In the first place, we will do some reflection on the different theoretical conceptions which attempt to explain how a language is acquired as well as its role in our nature as social beings. Moreover, we will approach the area of linguistic education after analysing the lexical and discursive uses in childhood through the presentation and description of samples that evidence a series of phenomena that range from the phonetic transgression and the peculiar configuration of the speechs to the aesthetic sense in the use of words.

KEYWORDS: creativity, oral speech, children's language, lexicon, communicative competence.

\section{INTRODUCCIÓN}

Encontrar el lugar de las palabras en el ser humano ha sido una cuestión abordada desde muy distintos ámbitos del saber; desde la antigüedad, 
filósofos, estudiosos del lenguaje, psicólogos, pedagogos y científicos han tratado de dar respuesta al modo en que los seres humanos accedemos al lenguaje, a qué mecanismos intervienen desde el deseo por comunicarnos con los demás hasta la emisión de una cadena de sonidos con carga semántica. Así, dónde establecer la frontera entre el código y la creación, dónde reside nuestra capacidad creativa, dónde ubicar el espacio para el sentido figurado, son algunas de las interrogantes en torno a las que han girado las reflexiones sobre la adquisición del lenguaje. Y es que conocer cómo aprendemos a hablar implica abordar un proceso muy complejo que nos hará oscilar entre lo que desde la perspectiva aristotélica vino a llamarse el terreno de las pasiones (Platón, 2003; Aristóteles, 2001) y la ejecución de la comunicación como herramienta social. Y decimos social porque defendemos que la facultad de hablar va más allá de un patrón anatómico. Encontramos en la actualidad grandes defensores del lenguaje como facultad biológica con afirmaciones como la siguiente: "el lenguaje es una actividad compleja y especializada que se desarrolla de forma espontánea en el niño, sin esfuerzo consciente o instrucción formal, se despliega sin que tengamos conciencia de la lógica que subyace a él, es cualitativamente igual en todos los individuos" (Pinker, 1995: 18). Ahora bien, tenemos que leer esta afirmación con mucha cautela, ya que tomada literalmente responde a una concepción del hablar ya superada desde que Ignacio de Luzán o, más adelante, Eduardo Benot definieran el concepto de un modo mucho más avanzado. La consideración de Pinker contrasta en gran medida con la concepción humanista mantenida en las investigaciones sobre la educación lingüística y literaria, para las que el factor social y el papel de la escuela y del mediador cobra una importancia fundamental. En qué lugar quedaría, de lo contrario, el papel de la retórica, esto es, el interés que desde la antigüedad grecorromana existió por el arte del bien hablar. Lo que está claro es que todos los seres humanos en sociedad acceden al lenguaje, cuentan con algo que les permite acceder al código; pero no todos adquieren la habilidad de elaborar discursos, por eso no podemos estar de acuerdo en que su dominio del habla sea "cualitativamente igual en todos los individuos". Esto es, no podemos decir que todos los hablantes hablen igual; todos usan el lenguaje, pero otra cuestión muy distinta es cómo lo usan. La explicación biológica (como también puede ser la del llanto) sí estará por igual en todos los seres humanos, pero no nos estamos moviendo en este terreno, sino en aquel que apuesta por el desarrollo del habla en tanto que habilidad comunicativa. Y en ese proceso cada individuo, cada circunstancia y cada mediador es completamente distinto. Hemos de tener muy claro que el concepto de habla hemos de entenderlo en el marco del discurso, como vía de comunicación entre miembros de una comunidad que interaccionan entre sí con textos organizados, de acuerdo a un sentido y a unas intenciones. En esto ha de centrarse la didáctica de la lengua. 
Otras disciplinas -como la lingüística clínica- también se han aproximado al habla entendiéndola como una habilidad motora o neurológica, de ahí que sea un terreno que se encuadra en un ámbito muy distinto al de la enseñanza de la lengua y la literatura, pues su interés vendrá orientado a las causas que expliquen trastornos o disfunciones derivados de alteraciones psíquicas o cerebrales. Por eso, el habla, desde la perspectiva de la educación lingüística, no puede abordarse como una cuestión anatómica, porque el arte de hablar está sujeto a un proceso formativo que, lejos de entenderlo como una capacidad física, lo va a concebir como una destreza comunicativa, de creación y apreciación estética que sí implica un aprendizaje. Aprender a hablar es uno de los grandes logros del ser humano desde que entra en contacto con las voces de quienes le rodean, con los sonidos y el compás de las canciones de arrullo y los juegos mímico-gestuales. Hablar le abre las puertas a su pensamiento para que sea transmitido con palabras en esa interacción que lo conforma como un ser social y que lo hace libre, porque le ayuda a afianzar sus señas de identidad (Quiles, Palmer y Rosal, 2015).

Nos encontramos, por tanto, ante una perspectiva distinta que se centra en el hablante como ser social y como tal el ámbito educativo le reviste un papel fundamental para su desarrollo a todos los niveles. Así, como usuario del lenguaje necesita evolucionar desde un conocimiento del código que podríamos llamar primario a una competencia en el manejo del discurso hablado y escrito. Todo esto estaría relacionado con un proceso de alfabetización, que muchas veces se asocia con materias del currículum que tienen que ver con destrezas muy básicas y que habría de entenderse desde una concepción mucho más amplia que llegue hasta el dominio en la elaboración de discursos en distintos contextos y distintos niveles de formalidad. Y que, por lo tanto, extienda su significado desde el código gráfico al plano del habla; pensemos que nuestras intervenciones orales nos ubican socialmente y determinan el grado de alfabetización que en definitiva tenemos. Así pues, es conveniente actualizar la función de alfabetizar, así como todos aquellos conceptos propios de la educación lingüística y literaria en una escuela plural, cambiante y tecnológica (Campos y Martos, 2013).

\section{ApRENDER A HABlar}

Es un hecho que el habla es una facultad que ha despertado numerosos debates en esa búsqueda de una explicación, no sólo sobre cómo se genera, sino también sobre el cómo se materializa en nuestra interacción como seres sociales. Noam Chomsky, en un profundo debate contra el conductismo de Skinner, defendería el factor genético para sustentar sus 
teorías. En Chomsky ya había un principio de capacidad creativa, en el sentido de que el ser humano construye estructuras gramaticales a partir de lo que nunca ha oído. Ahora bien, con las aportaciones de Piaget y Vigotsky sabemos que la creatividad en el lenguaje supone mucho más que este primer nivel relativo a las combinaciones de los elementos de un código, porque entra en juego el sentido de las palabras, la interpretación de los significados en contextos socio-culturales, las intenciones de los hablantes y su interacción en una determinada comunidad de usuarios.

Cuando nos planteamos buscar fórmulas para potenciar el desarrollo del lenguaje en las primeras edades, surgen diversos interrogantes en torno a su adquisición, al modo en que accede el niño al código lingüístico. Nos preguntamos cuáles serán las claves en ese proceso de inmersión en un sistema de comunicación determinado, el cual resulta ser básico para garantizar el conjunto de los aprendizajes en edad escolar. Se trata éste de un tema que ha suscitado profundas reflexiones desde las distintas miradas que lingüistas y psicólogos han presentado a lo largo del tiempo. Para ofrecer una primera aproximación, describiremos las principales aportaciones para obtener un panorama general que nos sirva de base sobre la que apoyar nuestro modelo de actuación didáctica.

La lingüística generativa vino a poner en duda, a través de diversos estudios, la idea de la imitación como puerta única para la adquisición del lenguaje. Si el niño "habla" imitando el modelo de sus semejantes, ¿cómo explicamos que existan fórmulas de uso en niños y niñas de todas las lenguas que rompen el esquema gramatical del adulto, de acuerdo al sistema de la lengua? Todos recordamos con toques de humor cómo nuestros pequeños nos dicen en contextos de la vida cotidiana "póneme los zapatos" -antes de salir al parque-, "yo quería que me hagara las coletas mi mamá" -cuando se marcha al colegio- o "no cabo" -al tratar de esconderse en un hueco de la casa-, pese a que tales combinaciones no han sido nunca escuchadas en boca de sus padres o cuidadores. Este ejemplo, atestiguado por los generativistas en el proceso de aprendizaje de todas las lenguas en los primeros años de vida del hablante, se une al hecho de que podemos establecer infinitas combinaciones gramaticales -que nunca hemos oído ni usado- a partir de unos elementos concretos.

Ambas evidencias vienen a demostrar la existencia de un componente innato en el ser humano que lo dota de la capacidad para acceder al lenguaje. Esta idea sería el principal presupuesto de las teorías de Noam Chomsky. Según Chomsky existe un Mecanismo -o dispositivo- de Adquisición del Lenguaje, LAD (Language Adquisition Device) que garantiza su acceso a lo que él llamó la competencia lingüistica. Al nacer, el ser humano cuenta con una predisposición para captar la "estructura profunda" de las lenguas, esos "universales lingüísticos" comunes a todas ellas -en todas los elementos 
se combinan, existen géneros, números,...- (Briscoe, 2000; McDonagh y McDonagh, 2009). Los planteamientos de Chomsky vendrían a romper con la idea conductista basada exclusivamente en el estímulo-respuesta, rechaza la mera imitación como desencadenante del desarrollo del lenguaje. Esta aportación supondría un pilar fundamental para explicar el acceso al uso de la lengua; sin embargo, serían necesarias otras reflexiones que completarían la teoría chomskiana. Hemos de tener en cuenta que el lenguaje es mucho más que una estructura, cuenta con niveles superiores al estrictamente sintáctico, puesto que podemos construir oraciones correctas en cuanto a los cánones gramaticales pero, al mismo tiempo, no comunicar nada, no transmitir una unidad de significado. En segundo lugar, no perdamos de vista que el lenguaje es ante todo comunicación y ésta comienza antes de que el niño sea capaz de manejar el código, la estructura, el sistema de la lengua. Los hablantes interaccionan mediante discursos completos, sujetos -como ya hemos resaltado- a un sentido y una intención, y esto es lo que nos dice que hablar es una destreza, no física, sino social.

Así, con Piaget avanzamos en el descubrimiento sobre el proceso de adquisición de las lenguas. Para este psicólogo la cuestión del significado es fundamental, puesto que según sus teorías el lenguaje no es más que una forma -como también lo puede ser el dibujo- de representar la realidad, es una actividad cognitiva, es el pensamiento quien lo dirige. No obstante, si bien Piaget da un paso más, su aportación carece del componente social. Él supera el mero componente genético en el proceso de adquisición y pone de manifiesto que el niño en su contacto con el mundo es quien construye el significado, pero admite que lo hace de forma autónoma. Sin embargo, es necesario retomar las teorías de Vigotski, un referente fundamental que, mucho antes, había aportado la idea de pensamiento y lenguaje, pero reconociendo que el desarrollo humano está garantizado por la interacción social. El niño se comunica antes de saber usar la lengua y es en esa comunicación donde surge el habla. Además, se parte de una concepción por encima del conocimiento de una serie de reglas. Aprender a hablar va más allá del dominio de una gramática; supone transmitir un pensamiento, hacerse entender de acuerdo a nuestra intención comunicativa, dominar códigos culturales, etc. Por eso, la interacción con el adulto va a resultar fundamental en todo el proceso.

Bruner, en la misma línea vigotskiana, resaltaba la función del adulto como mediador en el Sistema de Apoyo para la Adquisición del Lenguaje (LASS -Language Acquisition Support System-). Así lo exponía al afirmar que "la interacción entre LAD y LASS es lo que hace posible que el niño entre en la comunidad lingüística y, al mismo tiempo, en la cultura a la cual el lenguaje le permite acceder" (Bruner, 1986: 22). Y es que, hemos de dejar 
claro que acceder a una lengua, sea materna, segunda o extranjera, supone entrar en lo que podemos llamar una cultura idiomática, puesto que el habla viene marcada por toda una serie de convenciones culturales y sociales que la determinan de forma directa. La gestualidad, la entonación, la postura corporal, las fórmulas del saludo o de la disculpa, entre otros, son factores que dependen en gran medida de las concepciones de cada colectividad. Es, precisamente, la necesidad de crecer como ser social en el seno de dicha cultura lo que provoca las ansias de comunicación en el ser humano; en definitiva, el hombre usa el lenguaje como una forma de hacer cosas con palabras (Austin, 1988). Obviamente, lo anatómico nos ayuda a entender desde el punto de vista biológico algunos procesos en nuestras conductas y comportamientos; sin embargo, entendemos que no podemos perder de vista el aspecto social, puesto que el desarrollo del lenguaje necesita una interacción entre lo que sucede en nuestro sistema nervioso y lo que somos como seres sociales. Wittgenstein afirmaba que el límite de nuestro mundo es el límite de nuestra lengua, por lo que a medida en que avanzamos en su manejo aprendemos también a conectar con el mundo, a entenderlo y a interpretarlo ${ }^{1}$.

\section{USOS LÉXICOS Y CREATIVIDAD EN LA INFANCIA}

Siguiendo los presupuestos de Vigotsky y Bruner, somos conscientes de que la comunicación se inicia mucho antes de que el niño comience a hablar en su sentido más convencional. Desde que nace, la relación con la madre o primer cuidador, principalmente, le hace partícipe de una comunicación afectiva previa a la adquisición del lenguaje. El bebé experimenta su contacto con el mundo de los objetos a través de los sentidos, por lo que todo lo que percibe va a resultar clave para su desarrollo. En concreto, la voz humana tiene un gran atractivo para él, sobre todo su ritmo, su melodía, por eso esas primeras interacciones del recién nacido y su cuidador son esenciales para la futura adquisición del código lingüístico. En torno a los dos primeros meses de vida, comienza a descubrir que el llanto o la risa provocan las palabras del adulto: cuando él llora o emite sonidos el adulto le habla, por eso el bebé volverá a llamar su atención. Podemos decir que empieza a descubrir el proceso de la conversación a través de una interacción que se ha llamado protoconversación (Bateson, 1971 y 1979). Y todo ello protagonizado por la voz del adulto que en las rutinas diarias activa el proceso; desde su nacimiento, sus cuidadores le marcan un ritmo diario

${ }^{1}$ Recomendamos la visualización de la película Wittgenstein, de Derek Jarman (1993) (disponible en: <https://www.youtube.com/watch?v=IIu70Jo38eo>, con subtítulos en español). 
que él aprende a identificar y a ordenar a medida que pasan los días. De igual forma sucede con los formatos de juego.

En todas estas situaciones el aprendiz va entendiendo diversas fórmulas y poco a poco las irá comprendiendo también cuando sean usadas en otro contexto, esto es, pasará de la estructura profunda a la estructura superficial. Ese contacto con el mundo, propiciado por sus semejantes en las rutinas y en el juego, le ayudará a descubrir que todo lo de su alrededor es estable; en ese momento está preparado para identificar la relación entre esa realidad -las personas y los objetos- y una secuencia de sonidos, es decir, lo que Bruner denominó etiqueta lingüística -el nombre- que los adultos le han asignado (1986).

Tras unos meses de mayor lentitud en la adquisición del léxico, al acercarse los veinticuatro meses de vida el proceso se acelera. Llegados a este estadio nuestros pequeños ya manejan un número muy representativo de vocablos y van demostrando su agilidad para conectar unas palabras con otras, dentro de la creatividad que caracteriza sus combinaciones. Tengamos presente que una transgresión fonética, que muchas veces observamos desde un punto de vista superfluo, esconde en ocasiones un ejercicio de creación léxica; cuando un sujeto de ocho años nos dice que "la última etapa de la vida de los seres humanos es el envejimiento", en realidad no sólo está alterando el uso convencional del sufijo a partir del verbo envejecer -viejo-, sino a un proceso de analogía que lleva al emisor a comunicar una idea, sin duda adecuada y coherente, sin atender a los parámetros gramaticales de la lengua. De igual forma sucede con la expresión picapuntas; en este caso, la palabra compuesta -sacapuntas- ha sufrido una transformación asociada a su propio significado. Pero podemos ir más allá, puesto que los niños y niñas desarrollan una creatividad que los acerca a las producciones estéticas de una forma casi inconsciente. Expresiones como "te quiero como una nube de alto" o "este pan tiene pecas" demuestran la capacidad para elaborar un lenguaje muy próximo al literario y eminentemente creativo en las primeras edades. Por este motivo, esa habilidad que, como hemos apuntado, surge de la espontaneidad ha de ser potenciada desde la infancia hasta los niveles educativos más altos, algo que no suele ser una práctica habitual en nuestros centros. Todo ello sin detenernos en el lenguaje poético empleado de una forma inconsciente, haciéndoles productores de lo que podemos calificar como parametáforas, hipérboles y símiles constantes.

Aristóteles, Descartes, Ribot, Hume y Kant habían hablado de la imaginación como ese potencial que nos permite crear imágenes, experiencias nuevas a partir de lo vivido - percibido- y que es personal y diferente en cada uno de nosotros. La distancian del pensamiento, de la inteligencia, del juicio, aunque todo está conectado. Suárez realiza una reflexión muy interesante en este sentido, especialmente al hablar de la Poética de 
la ensoñación de Bachelard como eje sobre el que hablar de imaginación creativa en la infancia: "El niño, como el soñador, puede aproximar las cosas poéticamente y ensoñarlas para luego darles el rango de compañeras de lo humano ¿Por qué no pasar de la animación de los objetos, que tanto gusta a los niños, a su poética? Aquella alfombra mágica que de tapete de sala pasó a medio de transporte en la literatura es solo una muestra de lo que el niño o niña crea desde su imaginación en los juegos diarios" (Bachelard, 2009: 175).

La metodología observacional (Losada, 2000) se presenta como uno de los mecanismos más eficaces para descubrir todo tipo de procesos en la interacción cotidiana de los niños y niñas. Junto a ella, la focussed interview (Merton, Fiske y Kendall, 1956) reviste una gran utilidad para obtener muestras discursivas amplias que nos ofrezcan una representación variada de fenómenos. Recordemos las analogías y estructuras tan ingeniosas que son capaces de construir al hablar, como el uso de "encanastar una canasta" -en lugar de "encestar"-, "apréndeme una canción" -en lugar de "enséñame"-, "mañana es lejos" -en lugar de "mañana es tarde"-, "más antes" -por "mucho antes"-, entre otras. De esta forma, establecemos a continuación un análisis cualitativo de muestras recogidas de acuerdo con modelos de investigación empírica que nos han permitido registrar los fenómenos propios del habla infantil y de su escritura creativa. Dichas muestras fueron tomadas mediante la grabación audiovisual, técnica que nos permitía recoger no sólo la voz sino también la comunicación no verbal implicada en la elaboración de los discursos. Podemos resumir los rasgos más significativos de la siguiente forma:

FIGURA 1. Registro de muestras orales

\begin{tabular}{|c|c|c|}
\hline $\begin{array}{l}\text { FENÓMENOS FONÉTICOS / } \\
\text { LÉXICOS / GRAMATICALES }\end{array}$ & EJEMPlo / Muestra & SEXO Y EDAD \\
\hline \multirow{8}{*}{$\begin{array}{l}\text { Transformación fonética } \\
\mathrm{o} \text { invención de palabras }\end{array}$} & Atalajija (lagartija) & Niño, 3 años \\
\hline & Manganta (garganta) & Niña, 3 años \\
\hline & Gallena (ballena) & Niña, 34 meses \\
\hline & Agua paquita (agua fresquita) & Niña, 24 meses \\
\hline & Chorrea (correa) & Niña, 34 meses \\
\hline & $\begin{array}{l}\text { Desmerlúzamelo } \\
\text { (Desmenúzamelo) }\end{array}$ & Niña, 4 años \\
\hline & Toleito (culito) & Niña, 3 años \\
\hline & Capitán Calcio (Garfio) & Niña, 3 años \\
\hline
\end{tabular}


FiguRA 1. (cont.)

\begin{tabular}{|c|c|c|}
\hline $\begin{array}{l}\text { FENÓMENOS FONÉTICOS / } \\
\text { LÉXICOS / GRAMATICALES }\end{array}$ & EjEMPLO / Muestra & SEXO Y EDAD \\
\hline \multirow{4}{*}{$\begin{array}{l}\text { Asociaciones entre } \\
\text { sustantivos y acciones } \\
\text { para la formación } \\
\text { de verbos }\end{array}$} & Apréndeme una canción & Niña, 3 años \\
\hline & Quiero encanastar una canasta & Niño, 4 años \\
\hline & No quiero sacarme del agua & Niña, 34 meses \\
\hline & Gafas de capucear & Niña, 4 años \\
\hline \multirow{6}{*}{$\begin{array}{l}\text { Analogías gramaticales } \\
\text { en verbos y conceptos }\end{array}$} & Quería que me la hagaras tú & Niña, 3 años \\
\hline & Ponetelo en la cabeza & Niña, 3 años \\
\hline & Se me vola & Niña, 3 años \\
\hline & $\begin{array}{l}\text { Tuyúsculas } \\
\text { (frente a minúsculas) }\end{array}$ & Niña, 4 años \\
\hline & Derechera (frente a zurda) & Niña, 6 años \\
\hline & Cuando era pequeña me caíba & Niña, 3 años \\
\hline \multirow{5}{*}{$\begin{array}{l}\text { Reduplicación de pronombres } \\
\text { o construcciones confusas }\end{array}$} & Yo la quiero la pinza & Niña, 30 meses \\
\hline & Me la lo explicas & Niño, 6 años \\
\hline & Yo no me gustan las lentejas & Niña, 3 años \\
\hline & Quiero con $t u ́$ & Niña, 3 años \\
\hline & Tampoco yo no te tiero (quiero) & \\
\hline \multirow{5}{*}{$\begin{array}{l}\text { Desajustes gramaticales } \\
\text { (léxicos o semánticos) }\end{array}$} & Mañana es lejos & Niña, 3 años \\
\hline & Esta tarde no, hoy & Niño, 3 años \\
\hline & Me lo regaló mañana & Niña, 3 años \\
\hline & $\begin{array}{l}\text { Me lo habias prometido mañana / } \\
\text { Me lo prometiste mañana }\end{array}$ & Niña, 3 años \\
\hline & Tampoco no quiero jamón & Niña, 3 años \\
\hline \multirow{2}{*}{ Contradicciones léxicas } & $\begin{array}{l}\text { Yo tengo el pelo rizado porque } \\
\text { lo tengo liso }\end{array}$ & Niña, 3 años \\
\hline & $\begin{array}{l}\text { Yo ya soy muy mayor y es que yo } \\
\text { soy chiquitita }\end{array}$ & Niña, 34 meses \\
\hline \multirow{3}{*}{$\begin{array}{l}\text { Expresiones de juego } \\
\text { y sinsentidos }\end{array}$} & ¡Adios Laureta, peteta! & Niña, 5 años \\
\hline & ¡A pito, repito, pito, pito! & Niña, 3 años \\
\hline & ¡Adios mami mamut! & Niña, 5 años \\
\hline
\end{tabular}


FigURA 1. (cont.)

\begin{tabular}{|c|c|c|}
\hline $\begin{array}{l}\text { FENÓMENOS FONÉTICOS / } \\
\text { LÉXICOS / GRAMATICALES }\end{array}$ & EjEMPlo / Muestra & SEXO Y EDAD \\
\hline \multirow{9}{*}{$\begin{array}{l}\text { Expresiones figuradas } \\
\text { (lenguaje literario) }\end{array}$} & Andas como una tortuga & Niña, 4 años \\
\hline & Voy veloz como un rayo & Niño, 5 años \\
\hline & Los niños de la jaula & Niña, 4 años \\
\hline & Te quiero como una nube & Niña, 4 años \\
\hline & Pareces como una bruja & Niña, 5 años \\
\hline & Este pan tiene pecas & Niño, 4 años \\
\hline & ¡Soy un fantasma! & Niño, 4 años \\
\hline & $\begin{array}{l}\text { ¡Me voy a comer mil millones } \\
\text { de chuches! }\end{array}$ & Niña, 5 años \\
\hline & Las nubes viven en el cielo & Niño, 4 años \\
\hline
\end{tabular}

$\mathrm{Si}$ atendemos a los fenómenos fonéticos, léxicos y gramaticales presentados en la anterior tabla, podemos detenernos en comentar diversas cuestiones. No podemos negar la carga de humor que representan algunas de las emisiones de los informantes, puesto que al transformar las palabras aportan una carga lúdica a su lenguaje. Es el caso de "tuyúsculas" (por "mayúsculas) o "derechera" (por diestra), donde la lógica de la niña ha estado por encima de la norma, así como sus necesidades de comunicación; si decimos letras minúsculas y escribimos con la mano derecha, la tendencia lógica sería decir letras tuyúsculas y ser derechera. En "desmerlúzamelo" y en "Capitán Calcio", a la transformación fonética se le suma la asociación semántica con dos palabras conocidas para ellos: la merluza -que probablemente le desmenuce un adulto- y el calcio, ambas usadas en un contexto inapropiado, por asociación. Algo parecido sucede en "gafas de capucear", sintagma en el que se ha creado un vocablo compuesto nuevo a partir del sustantivo "capuzón” -“chapuzón”- y del verbo "bucear”. Otra de las cuestiones interesantes es su acercamiento al lenguaje figurado en el empleo de expresiones marcadas por un carácter retórico. Es el caso de las metáforas, por ejemplo, entre las que conviene explicar el uso de "los niños de la jaula”, puesto que solo en el contexto de su emisión podemos entender el lenguaje simbólico. La situación es la siguiente: los patios de dos colegios se separan por una verja laminada con una tela metálica, de forma que, para los de un lado de la valla, los escolares de la otra parte eran "los niños de la jaula". Este es uno de los ejemplos que viene a mostrarnos cómo el lenguaje es una forma de representar el mundo y, al mismo tiempo, de concebirlo. Además nos encontramos con los sinsentidos, las hipérboles, 
las personificaciones y los símiles, de uso muy frecuente en el habla cotidiana de los más pequeños. Un fenómeno curioso es la expresión "te quiero como una nube", pues demuestra una percepción por parte de la informante que asocia la altura a la cantidad. Es éste un proceso similar al que encontramos en "mañana es lejos"; en el lenguaje adulto la lejanía referida al tiempo y con el verbo ser la habríamos expresado como "mañana es tarde", según lo marcan las pautas gramaticales y las convenciones de uso.

\section{LA CONFIGURACIÓN DEL DISCURSO ORAL INFANTIL}

Por lo que respecta a los usos discursivos, veamos las transcripciones de dos muestras recogidas entre informantes en el tramo educativo infantil. La metodología seguida para la recopilación ha sido la misma que la expuesta en el apartado precedente:

FIGURA 2. Transcripción de relatos orales

\begin{tabular}{|c|c|c|}
\hline $\begin{array}{c}\text { TIPO } \\
\text { DE MUESTRA }\end{array}$ & TRANSCRIPCIÓN $^{2}$ & $\begin{array}{l}\text { SEXO } \\
\text { EDAD }\end{array}$ \\
\hline $\begin{array}{l}\text { Discurso } \\
\text { completo: } \\
\text { relato } 1\end{array}$ & $\begin{array}{ll}1 & \text { Y digió su mamá ahora a comer (endulzando la voz) si no } \\
2 & \text { no hay patio y digió este que no que no y digió este que si } \\
3 & \text { que sí y digio este que no y digio este que sí y entonces } \\
4 & \text { le dijo que no el v(c) uento se ha acabado (sonríe) }\end{array}$ & $\begin{array}{l}\text { Niña } \\
30 \text { meses }\end{array}$ \\
\hline $\begin{array}{l}\text { Discurso } \\
\text { completo: } \\
\text { relato } 2\end{array}$ & $\begin{aligned} 1 & \text { Había una ni:ña } \uparrow \text { que quería buscar a su abuelo } \uparrow \text { y como no lo } \\
2 & \text { encontra:ba } \uparrow \text { entonces llamó a su madre } \uparrow / \text { Entonces le dijo } \\
3 & \text { "mami mami el abuelo no me está cogiendo el teléfono } \uparrow \\
4 & \text { (endulzando la voz y subiendo el tono) / y entonces le di } \\
5 & \text { porque a lo mejor esta echando la siesta } \uparrow \text { o se ha ido a } \\
6 & \text { comprar fruta } \uparrow \text { /y entonces la ni:ña le dice a su madre: “puedo } \\
7 & \text { ir a la casa del abue:lo?” } \uparrow \text { (endulzando la voz) y su madre le } \\
8 & \text { dijo } \downarrow: \text { : "venga, vale, pero ten mucho cuidado” } \uparrow \text { / Entonces la } \\
9 & \text { niña } \uparrow \text { con cuidado } \uparrow, \text { se va a la casa de su abuelo } \uparrow / \text { y ento::nces } \uparrow \\
10 & \text { cuando está en el cami:::no } \uparrow \text { no no se acuerda dónde está la } \\
11 & \text { casa de su abuelo } \uparrow / y \text { entonces vuelve otra vez a su casa } \uparrow / \text { y } \\
12 & \text { entonces le dice a su madre: "mamá cme apuntas en en un } \\
13 & \text { un papel el dónde se va a la casa del abuelo?” } \uparrow \text { Y se va }\end{aligned}$ & $\begin{array}{l}\text { Niña } \\
5 \text { años }\end{array}$ \\
\hline
\end{tabular}

${ }^{2}$ Criterios de transcripción: cursiva para indicar el paralenguaje y la prosodia, $\uparrow \downarrow$ para indicar la ascendencia o decadencia tonal, ( ) para indicar los elementos suprimidos o alterados, : para indicar los alargamientos vocálicos, / para indicar las pausas y " " para indicar el diálogo dentro de la narración. 
Podemos observar cómo en el relato 1 la estructura narrativa, en un principio, parece amoldarse al patrón clásico de introducción, nudo y desenlace. Peterson y McCabe (1983) habían establecido siete patrones en el desarrollo de las narraciones emitidas por la infancia al contar sucesos trágicos. Efectivamente, la informante introduce la situación con el tópico "su mamá”, que nos da también el indicio de que el protagonista es un niño/a que pronto entrará en escena; a continuación asistimos al planteamiento del conflicto y, por último, se incluye una estructura de cierre. Sin embargo, ese patrón clásico sobre el que trata de edificar el discurso narrativo no se corresponde con el canon de relato adecuadamente construido. La niña intenta reproducir en la invención de su historia las pautas narrativas que tiene aprehendidas en su haber cognitivo a partir de las narraciones que le han contado. Pero, al mismo tiempo, su discurso coincide también con otros patrones que dichas autoras perfilaron en su estudio, tras analizar muestras orales: el patrón empobrecido y el patrón desorientado. Tengamos en cuenta que, por un lado, el cuerpo del texto es una reiteración de los mismos elementos, sin ofrecer información relevante ni explicar las causas ni efectos. Además, por otra parte, el mensaje es difuso, confuso y obliga al receptor a intuir qué está sucediendo y por qué. A todo ello, hemos de añadir el cierre abrupto de la historia "y entonces le dijo que no el v(c)uento se ha acabado".

Podemos establecer que serían cuatro los elementos clave a la hora de construir oralmente una historia, ya esté basada en un hecho real o ficticio ${ }^{3}$ :

a) situar al receptor en el tiempo y en el espacio,

b) presentar a los personajes y agentes del hecho narrado,

c) desarrollar los hechos de acuerdo a un orden lógico y cronológico, sin omitir información relevante,

d) concluir con un desenlace.

Tomando en cuenta lo anterior, esta muestra recogida a una informante de treinta meses, podemos decir que:

a) el texto no nos sitúa en el tiempo ni en el espacio. En este caso, el receptor adulto infiere por el contenido del mensaje que los personajes de la historia se encuentran en un espacio doméstico y a la hora de la comida, pero no es una contextualización que se aporte por la niña.

${ }^{3} \mathrm{Al}$ hablar de narración, muchas veces pensamos en la construcción de una ficción, de un hecho inventado, cuando una práctica muy habitual entre los hablantes infantiles es el relato de sucesos cotidianos de toda índole. Por ejemplo, se han publicado trabajos muy recientes que reflejan el modo en que los niños cuentan accidentes (Galván, Mendivelso y Betancourt, 2015), sin duda interesantes. 
b) el único personaje que se nos presenta es una madre, pero no se dice de quién, ni a quién se dirige con sus palabras.

c) de igual forma que todo lo anterior, los hechos han de ser intuidos por la persona que escucha. El contexto lingüístico nos lleva a pensar que la historia se desarrolla entre una madre y un hijo/a a la hora de la comida; la madre se enfada ante la negativa del hijo/a a comer y ella lo increpa con el castigo de no salir a jugar al patio en caso de que se siga negando.

d) El desenlace tampoco está claro ni descrito en forma alguna. La historia se cierra sin haberse planteado la resolución del conflicto, puesto que desconocemos si finalmente el niño/a pudo salir a jugar.

La elaboración adecuada de los discursos orales, tal y como venimos defendiendo, obedece a un aprendizaje que se va construyendo a partir del manejo de los niveles más básicos del lenguaje. A medida que la competencia lingüística se va convirtiendo en competencia comunicativa, la capacidad para elaborar discursos en el contexto formal irá aumentando. En este sentido, serán fundamentales los mecanismos de ilación textual, que nos permiten hilvanar una idea de forma ordenada -cohesión- al tiempo que nos ayudan a organizar el mensaje -coherencia-. Los estudios realizados hasta el momento en torno a los usos infantiles demuestran la necesidad de insistir en estos elementos. En este sentido, si volvemos la vista nuevamente al relato 1 , podemos observar que el mecanismo de conexión entre las distintas partes del discurso que usa la informante no es más que la conjunción copulativa "y", incluso seguida de "entonces" así como la suma y reiteración de elementos:

Figura 3. Fragmento de la muestra relato $1^{4}$

2 (...) $\mathrm{Y}$ *digió este que no que no. $\mathrm{Y}$ *digió este que si

3 que sí y *digio este que no y *digio este que sí y entonces

4 le dijo que no

En esta misma dirección, nos sirve de ejemplo el relato 2, emitido por una informante de cinco años. En esta segunda muestra se pone de manifiesto el abuso de la conocida muletilla léxica "entonces", unida en varias ocasiones a la conjunción copulativa "y":

\footnotetext{
${ }^{4} \mathrm{Al}$ tratarse de un fragmento extraído de la muestra transcrita, hemos marcado con * la agramaticalidad en el uso del verbo.
} 
Figura 4. Fragmento de la muestra relato 2

\begin{tabular}{|rl|}
\hline 2 & $(\ldots)$ entonces llamó a su madre / Entonces le dijo \\
4 & $(\ldots)$ y entonces le di \\
6 & $(\ldots)$ y entonces la ni:ña le dice a su madre: “¿puedo \\
8 & $(\ldots)$ Entonces la \\
9 & $(\ldots)$ y ento::nces, \\
11 & $(\ldots)$ y entonces vuelve otra vez a su casa / y \\
12 & entonces le dice a su madre: \\
\end{tabular}

Esto es producto del hecho de que los escolares a estas edades trasladan los mismos modelos discursivos de su habla coloquial a los ámbitos formales o académicos. Esto es, su manejo del lenguaje se muestra ajeno a la distinción entre los distintos registros idiomáticos. Además, se trata de un fenómeno que ya venimos atestiguando a través de los diversos estudios previos realizados, no solo en las edades tempranas sino también en las etapas escolares más avanzadas. Cuando a finales de los ochenta comenzó a hablarse de la sintaxis del coloquio, los marcadores del discurso hablado empezaron a ocupar las páginas de investigadores como Narbona Jiménez (1988), Cortés Rodríguez (1991), Vigara Tauste (1992) y Pons Bordería (1998) y se perfilaron de forma exhaustiva los valores y funciones del adverbio temporal "entonces" en tales contextos de habla por parte de interlocutores adultos. La pregunta sería si tales usos son extrapolables al ámbito infantil. O mejor dicho, quizás en esta interrogante encontremos la respuesta, puesto que más bien el adulto viene arrastrando unos usos comunicativos adquiridos y asentados en su haber desde su más tierna infancia. O dicho de otra forma, la ausencia de planes curriculares sólidos para una enseñanza del discurso oral viene provocando que la escuela dé por hecho que a hablar se aprende espontáneamente. La prueba de que tal presupuesto no es cierto sale a flote cuando escuchamos y analizamos la configuración discursiva de narraciones orales emitidas por niños de distintas edades, por adolescentes y por adultos. El uso y abuso de tales partículas es una evidencia en todas ellas porque no se nos ha capacitado a lo largo de nuestra vida académica para ubicarnos en el discurso hablado en contextos formales. Tengamos en cuenta que los estudios citados nacieron en torno al coloquio, en torno a un registro de lengua informal. Lo que nos preocupa desde la educación lingüística es su progresiva y continua traslación al ámbito académico.

Siguiendo con la muestra relato 2 vemos cómo "entonces" es el único marcador del discurso empleado, despojado de toda su carga semántica 
-en tanto que adverbio temporal, e incluso en su dimensión modal- al convertirse en una mera palabra de relleno sobre la que sumar las ideas, de ahí que su relato se construya como una simple unión de estructuras y queda vacío de sentido estético, de pautas estilísticas y de decoro en el bien hablar. Adquiere el valor de una conjunción copulativa, aunque hemos de tener en cuenta en muchos casos su carácter polifuncional desde el punto de vista prosódico-discursivo, dado que la variabilidad tonal y el alargamiento vocálico ofrece matices distintos. Dorta y Domínguez (2004) o Martínez Hernández (2015) han estudiado este aspecto en los marcadores del español hablado. En el caso que nos ocupa hemos de tener en cuenta dos cuestiones: se trata de un discurso infantil y se emite en un contexto formal (lo cual no quiere decir que no exista una traslación de los patrones de habla coloquiales, según ya hemos expuesto). Los entonces recogidos en esta muestra oscilan entre la función organizativa y la función consecutivo-procondicionante, siguiendo las funciones establecidas por Dorta y Domínguez (2004). Por un lado, ese "entonces" es la única herramienta lingüística usada para organizar la información, aparece en el interior de la intervención y tras una pausa (aunque en este caso no es larga); y al mismo tiempo, lo que va introduciendo son consecuencias de lo anterior y enlazando con lo que sucederá a posteriori, además de mantener la ascendencia tonal en toda la frase. Precisamente esa reiteración del tono y la repetición de su uso en un espacio tan corto del relato es la que le confiere un valor sumativo de ideas y estructuras gramaticales. No se trata de un uso consciente ni secuenciado.

En cuanto a la construcción de la historia, en esta muestra observamos una evolución con respecto a la anterior, pero es obvio que no se trata de un discurso narrativo bien organizado:

a) La informante acude a la fórmula de los cuentos tradicionales al iniciar con la forma verbal "había”, trasladándose al pasado y estableciendo un distanciamiento de la realidad para entrar en la ficción. Sin embargo, no realiza una ubicación precisa no sólo con respecto al tiempo, sino también en cuanto al espacio. El receptor es quien debe intuir dónde comienza la historia, en la casa de la protagonista; posteriormente se anuncia el "camino", pero de inmediato la escena regresa de nuevo al espacio inicial, la casa. Tampoco se nos indica el lugar de destino, esto es, dónde está la casa del abuelo. La salida a través de un camino nos recuerda el paseo de Caperucita, si bien se introducen elementos actuales como el teléfono. Observamos, por tanto, cómo se conjugan los modelos estéticos del imaginario colectivo con las propias experiencias de vida a estas edades. 
b) Los personajes se introducen desde el primer momento, si bien no se aporta ningún dato sobre ellos, como si fueran agentes vacíos de contenido. Apreciamos la ausencia de variedad léxica, de pautas estilísticas y recursos que embellezcan el relato. De esa forma, no se ayuda al receptor a recrear una imagen mental de los protagonistas: la niña, la madre y el abuelo, porque no sabemos nada sobre ellos.

c) Aunque los hechos se describen sin alteraciones cronológicas demasiado importantes, se echa en falta un discurso fluido, un mayor orden en las ideas narradas. Las continuas vacilaciones y la omisión de información relevante exigen un esfuerzo añadido al interlocutor a la hora de ubicarse y seguir el curso de los acontecimientos.

d) La forma de cierre, como sucedía en la muestra relato 1, es del todo abrupta. Se han contado los hechos de una manera excesivamente sintética y, además, el desenlace ha quedado sin exponer. En realidad, no sabemos cómo acaba la historia.

Todo este análisis nos lleva a defender la necesidad de una didáctica del discurso oral que, desde las primeras edades, garantice una educación lingüística basada en el desarrollo de la creatividad y la capacidad para expresar el pensamiento con palabras. Hemos de tomar en cuenta un marco sobre el que edificar nuestros procesos de enseñanza-aprendizaje en torno al bien hablar.

\section{Discurso, CREATIVIDAD Y EDUCACIÓN LINGÜÍSTICA}

Podemos decir que el aprendiz va entrando en la dinámica del discurso, entendido como eje de la comunicación. En este sentido, hemos de resaltar el alcance de este concepto según las directrices emanadas no sólo a partir de la Lingüística Textual, sino también de la Pragmática Lingüística y del Análisis del discurso. La primera de estas disciplinas nos situó ante la necesidad de contemplar el lenguaje más allá de la oración, en tanto que un conjunto en el que el sentido se adquiría en la totalidad de sus sintagmas y enunciados. La Pragmática Lingüística ha venido a poner de manifiesto la importancia de los usos comunicativos en función del contexto y los propios usuarios, unida a los estudios en torno al discurso. El Análisis del discurso, en consonancia con los estudios pragmáticos, viene ayudando en los últimos años a configurar el modo en que los hablantes organizamos nuestras interacciones. Afirma Cortés que "de ahí el desarrollo paralelo e interrelacionado que en el análisis del discurso oral del español han tenido el análisis del discurso y la pragmática, desarrollo que ha hecho que ambas 
disciplinas parezcan cada vez más la misma cosa, aunque evidentemente no lo sean. La pragmática es un conjunto de principios teóricos de los que se aprovechan las distintas metodologías del análisis del discurso; por ello, al menos en nuestros días, sus avances se entremezclan" (2002).

Hablamos de una competencia pragmático-discursiva necesaria para el desarrollo pleno de la competencia comunicativa en todo usuario de una lengua determinada. Podemos decir que "la definición del discurso como lengua en uso es coherente con el funcionalismo en general: se ve al discurso como un sistema (como una forma de hablar social y culturalmente organizada) a través del cual se realizan funciones particulares. Si bien pueden muy bien examinarse regularidades formales, una definición funcionalista del discurso aleja al analista de las bases estructurales de dichas regularidades para centrarse en el modo en que los patrones del habla se usan para ciertos propósitos en contextos particulares, y/o de qué modo dichos patrones resultan de la aplicación de estrategias comunicativas [...] No es, pues, sorprendente que se basen menos en las características estrictamente gramaticales de la emisiones, que en la manera en que las emisiones se sitúan en contextos" (Schiffrin, 2011: 16).

Frecuentemente, cuando afirmamos que el niño ya habla y supera el estadio de la más tierna infancia, damos por hecho que ya sabe usar el lenguaje; suele ocurrir al llegar a la escuela Primaria. Sin embargo, hemos de preguntarnos qué elementos de ese lenguaje emplea, cómo, con qué mecanismos y para qué lo emplea. Los contextos que lo rodean son muy diversos, así como sus intenciones comunicativas, de manera que no siempre están preparados para un uso eficaz de su lengua. Su mundo de juegos, los intercambios cotidianos marcados por la coloquialidad no suponen -aparentemente ${ }^{5}$ - ningún problema; por el contrario, las situaciones formales, cultas y académicas sí que se convierten en espacios complejos para desenvolverse con soltura. Es cuando entra en juego la capacidad para organizar nuestros discursos, una capacidad que ha de aprenderse y desarrollarse.

Si revisamos los relatos recogidos en la figura 2, podemos observar los rasgos más característicos que presenta el discurso infantil. Ante tales situaciones comunicativas, por encima de las habilidades fonoarticulatorias o los ajustes gramaticales, nos va a interesar la configuración del discurso, esto es, el modo en que se nos traslada el pensamiento: el orden de las ideas, la conexión de unas partes con otras, la adecuación al registro, el

\footnotetext{
${ }^{5}$ Decimos aparentemente porque, incluso en los momentos de mayor coloquialidad, surgen necesidades de mejora en los intercambios comunicativos. Pensemos en un partido de fútbol ante el cual todos los interlocutores pretenden defender sus argumentos; en este caso se pasan por alto muchas de las convenciones que regulan este tipo de discurso, como el respeto de turno de palabra, la cortesía verbal, etcétera.
} 
estilo, etc. Y es que cuestiones como el hecho de decir "dijió" en lugar de "dijo" van a ser superadas a medida que evolucionen como seres sociales, mientras que el resto de habilidades a las que hemos aludido en raras ocasiones se adquieren sin un aprendizaje, sin un refuerzo educativo. Ha quedado demostrado a través de distintos trabajos empíricos (Quiles, 2002 y 2004) que el patrón discursivo de los niños y niñas en contextos formales poco varía desde su más tierna infancia hasta la Educación Secundaria e incluso a la superior; las mismas necesidades de mejora que presenciamos en Infantil se continúan atestiguando en los niveles de Primaria en adelante. Probablemente, mucho tendrá que ver que las destrezas pragmático-discursivas ocupan un espacio de tiempo casi invisible en la práctica educativa diaria, especialmente en lo referido a la lengua oral.

La atención pedagógica, por tanto, ha de dirigirse en una doble dimensión: la transmisión del pensamiento con palabras orales y con palabras escritas. El discurso oral y el discurso escrito habrán de convivir en armonía en toda proyección educativa que pretenda promover la competencia comunicativa desde el inicio de la escolarización, para lo cual es imprescindible que los educadores tengan muy claro qué es hablar y qué es escribir; o dicho de otro modo, cuál es el marco de la oralidad y el marco de la escritura. Mucho se ha escrito ya sobre la oposición entre oralidad y escrituridad con la intención de alejarnos de concepciones que nos llevan a pensar que hablar bien no es otra cosa que hablar como se escribe. Sabemos que la esencia en la elaboración de los discursos orales y escritos reside en otras cuestiones, además de compartir un mismo código -esto es, una misma gramática-. De ahí la importancia de elementos como la coherencia y la cohesión textual, los marcadores del discurso, los mecanismos pragmáticos y sociolingüísticos o la gestualidad y la prosodia -que se manifiestan en el habla y no en la escritura- (Quiles, 2012).

Además, hemos de tener en cuenta los nuevos espacios y formas del discurso que se han generado en los últimos años con la llegada de las Tecnologías de la Información y la Comunicación. La mensajería de los teléfonos móviles supuso el inicio de un juego con las palabras que se ha extendido a todas las edades y ámbitos, así como Internet ha dibujado un panorama extenso de modalidades discursivas. Las páginas web, los blogs y las redes sociales suponen espacios de comunicación a medio camino entre lo oral y lo escrito con unas características propias en las que la interacción entre los interlocutores es dinámica y se renueva casi con la espontaneidad del habla. No sólo han supuesto un cambio en la forma de los discursos, sino también en el modo y en los rasgos que definen ese tipo de escritura. Además, las TIC nos ofrecen herramientas que nos permiten mantener conversaciones en la distancia con la presencia física y visual de los hablantes; nos referimos a la videoconferencia y a plataformas como el skype. Todo 
esto, desde el punto de vista educativo, nos aporta múltiples posibilidades de trabajo a la hora de unir el lenguaje creativo a la enseñanza de una lengua formal y también con un sentido estético. Incluso la creación literaria se ve reflejada en la web, mediante páginas interactivas a modo de taller de escritura y los llamados hipercuentos o hipernovelas en el ámbito de la literatura electrónica ${ }^{6}$ y la ciberliteratura (Aarseth, 2006).

En este sentido, para concluir, hemos de insistir en las posibilidades pedagógicas que nos ofrecen los nuevos espacios en red a la hora de potenciar el desarrollo de las habilidades discursivas orales, como ya hemos mencionado. Los estudiantes están familiarizados con las tecnologías de la información y la comunicación de tal forma que suponen uno de sus principales ejes de comunicación a lo largo del día. Todo comenzó con la mensajería móvil y el correo electrónico, pero se ha ido ampliando con las redes sociales, los blogs y toda una serie de herramientas que nos permiten, desde nuestro ordenador, acceder al texto oral con una facilidad mucho mayor que hace algunos años. La aparición de programas como Audacity (<http://audacity.softonic.com>), por ejemplo, ha supuesto un paso hacia adelante en este sentido. Mientras ayer necesitábamos una videocámara o una grabadora para fijar en el tiempo y en el espacio la oralidad, hoy desde nuestra mesa de trabajo podemos crear nuestros textos orales en un soporte que equivaldría al papel para el lenguaje escrito. Y además, podemos compartirlo con otros usuarios. Es lo que se conoce como la creación de las llamadas Postcards. Podríamos mencionar también la página Spreaker (<http://www.spreaker.com/>), que nos permite crear nuestro propio programa de radio. Interesantes son también los conversores de texto en audio, como es el caso del llamado Dspeech $(<\mathrm{http} / / /$ dspeech. softonic.com/relacionadas $>$ ).

Otro de los recursos en línea que nos interesa destacar lo constituyen las fonotecas y los bancos de corpus orales que nos ofrece la red desde organismos e instituciones oficiales. Estos espacios constituyen un complemento básico a la hora de incorporar los discursos orales al aula, de igual forma que viene haciendo la tradición escolar con los textos escritos. Si la escuela no concibe enseñar a escribir sin manejar los textos escritos como referencia, enseñar a hablar no puede lograrse con éxito si los aprendices no

${ }^{6}$ Un ejemplo de hipernovela puede ser la titulada Como el cielo los ojos, de Edith Checa (disponible en <http://www.badosa.com/bin/obra.pl?id=n052>, página consultada el 29 de diciembre de 2015). Con respecto a la literatura electrónica, recomendamos visitar el Portal de Literatura Electrónica Hispánica de la Biblioteca Virtual Miguel de Cervantes, disponible en <http://www.cervantesvirtual.com/bib/portal/literaturaelectronica/presentacion.jsp>, página consultada el 29 de diciembre de 2015. Puede consultarse también la página de Taller de Escritura (de Enrique Páez, escritor) en <http://www.tallerdeescritura.com/>, consultada el 11 de enero de 2016. 
entran en contacto con los discursos orales en la misma medida. Así pues, las fonotecas vienen a cubrir el vacío que presentan los libros de texto, centrados en el desarrollo de la escritura y caracterizados por un tratamiento del habla extremadamente superficial en la mayoría de los casos. La fonoteca del Centro Virtual Cervantes (<http://www.cervantesvirtual.com/ fonoteca/ $>$ ), por ejemplo, nos permite acceder a discursos orales de distinta índole, desde el género ensayístico hasta el poético. Interesante resulta también el centro de corpus CREA ORAL, de la Real Academia de la Lengua (<http://www.rae.es/recursos/banco-de-datos/crea-oral >). La efectividad del uso de estos corpus para el desarrollo de las habilidades comunicativas orales en el ámbito educativo se ha demostrado en el contexto de aprendizaje de lenguas extranjeras, como ha sido el caso de la Universidad de Bergen (Danbolt, 2008), donde se empleó el corpus en línea del proyecto COLA (Corpus Oral de Lenguaje Adolescente) (<www.colam.org $>$ ), dirigido por la profesora Jørgensen (Jørgensen y Eguì, 2008). El empleo de tales materiales nos da la pauta para su uso en las aulas de español como lengua materna, para abordar el proceso de aprendizaje de las destrezas orales. Existen otros corpus que han surgido en el seno de otros proyectos y que han sido divulgados a través de publicación en CD. Es el caso de C-ORAL-ROM (<http://www.lllf.uam.es/ESP/Coralrom.html $>$ ). Todas las muestras allí recogidas pueden ponerse en uso dentro de las aulas, en los programas para la educación lingüística, con el fin de poner al alumnado en contacto con emisiones orales extraídas de su propio contexto de producción. Sostenemos que tales herramientas van a resultar de gran utilidad a la hora de abordar una enseñanza del discurso desde una perspectiva no sólo comunicativa, sino también estética, de acuerdo con el canon y el juego con el lenguaje ${ }^{7}$.

\section{Conclusión}

Para la Didáctica de la Lengua, el análisis aislado de las muestras textuales nos ofrece un diagnóstico sobre las destrezas adquiridas por los aprendices y sus necesidades de mejora, pero quedarnos sólo en esta fase sería insuficiente. Es necesario tomar ese diagnóstico como base para iniciar un proceso didáctico que desarrolle las destrezas discursivas. Sabemos que el mismo hecho -real o imaginario- puede contarse de formas muy distintas, pero ese modo en el que lo contamos va a determinar su eficacia pragmática, esto es, que sea entendido de la forma en que debiera. A ello

${ }^{7}$ Véase el Taller de la editorial SM en <http://www.primaria.profes.net/especiales2.asp? id_contenido=39676>, página consultada el 12 de enero de 2016. 
no sólo va a contribuir la corrección gramatical, sino también las pautas de estilo, el lenguaje figurado, la riqueza léxica y la organización de las ideas.

Hemos hablado de la necesidad de trabajar la elaboración de los discursos en sus múltiples modalidades y contextos formales. Pero, al mismo tiempo, es importante fomentar el lenguaje creativo. Pensemos que se trata de dos ámbitos que en absoluto han de estar reñidos; el uso del lenguaje como juego, de acuerdo con la libre expresión del pensamiento va a venir a complementar la adquisición de destrezas para abordar situaciones de comunicación cultas o académicas. Aprender a hablar y a escribir con adecuación viene unido al hecho de que los usuarios tengan cosas que decir y sepan cómo decirlas; para ello lo más importante es estar entrenado. La tradición escolar ha venido marcada frecuentemente por una serie de prácticas, sobre todo las escritas, centradas en la reproducción -copiados y dictados-, el aprendizaje del código -gramática- y la lectura comprensiva. Se trata de tareas necesarias, pero no olvidemos que a través de ellas sólo cubrimos los niveles más básicos de la educación lingüístico-literaria y, sin duda, perseguimos otras metas. La mayor parte de las veces, en las aulas, no queda lugar para el lenguaje creativo; en el mejor de los casos la escritura lúdica se reduce a la composición de un poema libre de forma voluntaria, coincidiendo con un día festivo o señalado. Ahora bien, lo que no podemos olvidar es que en la medida en que la escuela nos haya preparado para desenvolvernos hablando o escribiendo, en la medida en que nos haya enseñado a transmitir nuestros pensamientos, emociones o experiencias y a entender y usar nuestra lengua como un instrumento de comunicación, de juego o de goce estético, habremos avanzado en favor de una más o menos próspera educación lingüística. Podemos decir que "además de la inadecuación léxica, por ejemplo, lo que en estos casos falla no es otra cosa que la buena elaboración de los discursos en función de las pautas que rigen la coherencia y la cohesión de las ideas. Por lo tanto, estos aspectos debieran ocupar también el centro de nuestra atención en esa formación lingüística que pretendemos ofrecer al alumnado, para que el proceso de aprendizaje de la lectoescritura no se dé por concluido demasiado pronto" (Quiles, Palmer y Rosal, 2015: 32). Y es que el desarrollo de la composición escrita, unido y paralelo al de la composición oral, establecerá puentes de acceso desde la una a la otra, aprendiendo a ubicar el grado de formalidad, a organizar nuestros discursos y a elegir de nuestro léxico tanto en una como en otra modalidad. 


\section{BIBLIOGRAFÍA}

Alturo, N. (2010): "Coherencia discursiva: Dimensiones contextual, conceptual y gramatical”, Círculo de Lingüistica Aplicada a la Comunicación, 41, $<$ http://www.ucm.es/info/circulo/no41/index.htm>.

Álvarez Angulo, T. (2002): "La magia del lenguaje de los niños", Didáctica (Lengua y Literatura), 14, págs. 23-36.

Aarseth, E. et al. (2006): Teoría del hipertexto: la literatura en la era electrónica, Madrid, Arco/Libros.

Austin, J. L. (1988): Cómo hacer cosas con palabras: palabras y acciones, Barcelona, Paidós.

BAÑón, O. (2010): Etapas del desarrollo del lenguaje, Don Benito, Edita.

Bateson, M. C. (1971): "The interpersonal context of infant vocalization", Quarterly Progress Rep. Res. Lab. Electronics, 100, págs. 170-176.

- (1979): "The epigenesis of conversational interaction”, en M. Bullowa (ed.), Before speech: the beginnings of human communication, Londres, Cambridge University Press, págs. 63-77.

BRISCOE, T. (2000): "Grammatical Acquisition: Inductive Bias and Coevolution of Language and the Language Acquisition Device”, Language, 76, 2, págs. 245-296.

Bruner, J. (1986): El habla del niño. Cognición y desarrollo humano, Barcelona, Paidós.

Campos, M. y Martos, E. (2013): Diccionario de nuevas formas de lectura y escritura, Madrid, Santillana.

Cortés, L. (1991): Sobre conectores, expletivos y muletillas en el español hablado, Málaga, Ágora.

- (2002): "La incorporación de los estudios pragmáticos al análisis del discurso oral en español". Tonos Digital: Revista Electrónica de Estudios Filológicos, 3, $<$ http://www.um.es/tonosdigital/znum3/estudios/EstudiosPragLuisCortes.htm>.

- y Самасно, M- M. (2003): Qué es el análisis del discurso, Barcelona, Octaedro.

- y MuÑío, J. L. (2008): "Sobre por qué ha de enseñarse la lengua oral y cómo puede hacerse", Textos de didáctica de la lengua y la literatura, 49, págs. 57-66.

DanBolt, E. M. (2008): "Un corpus oral en línea como recurso didáctico", Actas del II Congreso Nacional ANPE: Multiculturalidad y norma policéntrica: aplicaciones en el aula de ELE (<http://www.colam.org/ANPE-2008-Drange-1.pdf>).

Deutscher, G. (2011): El prisma del lenguaje: cómo las palabras colorean el mundo, Barcelona, Ariel.

Dorta, L. y Domínguez, N. (2004): "La prosodia y las funciones de los marcadores del discurso", en M. Villayandre (ed.), Actas del V Congreso de Lingüistica General, Madrid, Arco/Libros, págs. 757-771.

EsCANDELL, Ma V. et al. (2009): El lenguaje humano, Madrid, Editorial Universitaria Ramón Areces. 
España, A. (2011): El desarrollo del lenguaje, Don Benito, Edita.

FERnÁndez, P. (1996): "Modelos sobre la adquisición del lenguaje”, Didáctica, 8, págs. 105-116.

ForTE, E. (2010): Filosofía del lenguaje, Madrid, Bubok.

Fuentes, C. (2000): Lingüistica pragmática y análisis del discurso, Madrid, Arco/Libros.

Galván, Z., Mendivelso, M. y Betancourt, Y. (2015): "La estructura narrativa en el discurso infantil: un enfoque psicosociolingüístico”, Lingüistica y Literatura, 68, págs. 37-56.

Gleason, J. B. y Bernstein, N. (2010): El desarrollo del lenguaje, Madrid, Prentice Hall.

GonzÁlez, A. B., PÉREZ, A. y SÁnChez, A. (2011): Me comunico con el mundo: desarrollo del lenguaje, Vigo, Nova Galicia Edicions.

HallidAY, M. A. K. (1982): El lenguaje como semiótica social, México, FCE.

Jørgensen, A. M. y Eguìa, E. (2008): "COLA: Un corpus oral de lenguaje adolescente", Anejos de Oralia, 3, 1.

LÁzAro, L. y LÁZARo, Ma A. (2011): Desarrollo cognitivo y del lenguaje en Educación Infantil y Primaria, Granada, K\& L.

LóPEZ, P. (2010): Lenguaje creativo en el aula, Zaragoza, Movimiento de Renovación Pedagógica "Aula Libre".

Martínez Hernández, D. (2015): "La importancia del factor prosódico en el estudio de los marcadores del discurso: algunos problemas de su análisis acústicomelódico", CLAC, 62, págs. 105-124.

McDonagh, J. y McDonagh, S. (2009): "Learning to talk, talking to learn", en J. Marsh y E. Hallet (eds.), Desirable Literacies. Approaches to Language and Literacy in the Early Years, Londres, Sage, págs. 1-17.

Miretti, M ${ }^{\mathrm{a}}$ L. (2003): La lengua oral en la educación inicial, Santa Fe (Rosario), Homo Sapiens.

O'Grady, W. (2010): Cómo aprenden los niños el lenguaje, Madrid, Akal.

PAHL, K. (2009): "Looking with a different eye: Creativity and literacy in the early years", en J. Marsh y E. Hallet (eds.), Desirable Literacies. Approaches to Language and Literacy in the Early Years, Londres, Sage.

- (2012): "A Reason to Write. Exploring writing epistemologies in two contexts", Pedagogies: An International Journal, 7, 3, págs. 209-228.

Peterson, C. y McCabe, S. (1983): Development Psycholinguistics: Three Ways of Looking at a Child's Narrative, Nueva York, Plenum Press.

Pinker, S. (1995): El instinto del lenguaje, Madrid, Alianza Editorial.

Pons Bordería, S. (1998): Conexión y conectores: estudio de su relación en el registro informal de la lengua, Valencia, Universidad de Valencia.

Quiles, Ma C. (2002): Didáctica del discurso oral, Almería, Universidad de Almería.

- (2004): "Los usos orales en edades tempranas", Revista Española de Lingüistica, 34, 2, págs. 567-577.

- (2012): "El rescate de la palabra: discurso, oralidad y educación lingüística en la escuela”, en Sánchez y Ramos, Compromiso docente y realidad educativa: retos para el maestro del siglo XXI, Madrid, Síntesis, págs. 219-234. 
—, Palmer, I. y Rosal, M. (2015): Hablar, leer y escribir. El descubrimiento de las palabras, Madrid, Visor.

RAPHAEL, P. (2011): La fábrica del lenguaje, Barcelona, Anagrama.

SCHIFFrin, D. (2011): "Definiciones de discurso. CPU-e", Revista de Investigación Educativa, 13 <http://www.uv.mx/cpue/num13/practica/Schiffrin>.

SuÁrEz, M. L. (2009): "La experiencia de la imaginación creadora como elemento primordial de la creación poética en la infancia”, Civilizar, 9, 17, págs. 169-180.

Tomé, M. (2009): "Enseignement des langues, communication et compétences orales sur le web actuel”, Cédille: revista de estudios franceses, 5, págs. 347-370.

Vigara TAuste, A. M-1 (1992): Morfosintaxis del español coloquial. Esbozo estilístico, Madrid, Gredos.

Vigotsky, L. (1992): "Estudios sobre la historia de la conducta (Mono. Hombre primitivo. Niño)", en Luria y Vigotsky, Ape, Primitive Man, and Child: Essays in the History of Behaviour, Harvester Wheatsheaf <http://www.marxists.org/ archive/vygotsky/works/1930/man/index.htm>. 